\title{
Heavy Metal Loadings to the Detroit River from Combined Sewer Overflows
}

Nadia El-Sayed, Zeinab Sayed Abdel-Rehim, Yinlun Huang, and Ralph H. Kummler

The calculation of 1995 pollutant loads from the Conner Creek Combined Sewer Overflow (CSO) discharging to the Detroit River is presented in this work. The chemical analysis of selected heavy metals $(\mathrm{Cd}, \mathrm{Cr}, \mathrm{Cu}, \mathrm{Fe}, \mathrm{Pb}, \mathrm{Zn})$ which have a high toxic potential for the Detroit River is given. The United States Geological Survey (USGS) measurement data (1995) is utilized to compute the load of these toxicants to the Detroit River. These data include the concentrations of constituents and the volumetric discharge flow rates of the CSOs. The 1995 concentrations and loadings are compared with 1979 measurements and calibrated computer predictions. The results show that the 1995 concentrations and loadings for CSOs to the Detroit River are less than the 1979 concentration and loading estimations for most of the selected contaminants at the Conner site.

\subsection{Introduction}

The Conner Creek Combined Sewer Overflow (CSO), as one of the most important CSOs flowing into the Detroit River near its headwaters, has been the subject of numerous studies, most recently the 1996 Detroit River Remedial Action Report Update (MDNR, 1996) and the Southeast Michigan Council of Governments (SEMCOG) Detroit River Toxics Studies (SEMCOG, 1997).

El-Sayed, N., Z.S. Abdel-Rehim, Y. Huang and R. Kummler. 1999. "Heavy Metal Loadings to the Detroit River from Combined Sewer Overflows." Journal of Water Management Modeling R204-13. doi: 10.14796/JWMM.R204-13.

(C) CHI 1999 www.chijournal.org ISSN: 2292-6062 (Formerly in New Applications in Modeling Urban Water Systems. ISBN: 0-9697422-9-0) 
Pollution in the Detroit River has been classified into organic, metal, heavy metal, and inorganic pollutants. The work summarized here deals only with heavy metals. The Detroit River provides important habitat for fish, birds and mammals. Atmospheric transport and deposition of chemical constituents over the entire basin, leakage from Michigan's Act 307 (now 201) contamination sites (MDNR, 1993), and industrial effluents to the system are all potential Detroit River sources of a variety of toxic chemicals through the CSO outfalls. The Detroit River Toxics study (SEMCOG, 1997) sought to quantify those loadings. This work describes some of those results for the Conner Creek CSO located as shown in Figure 13.1.

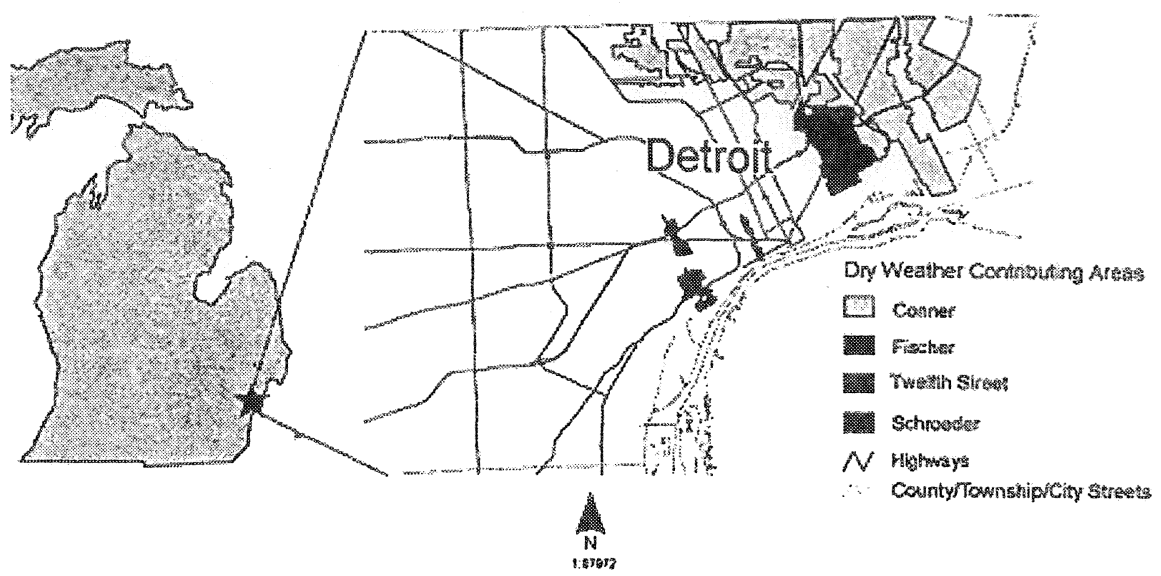

Figure 13.1 A map of the study area.

\subsection{Background}

Treated and untreated wastewater from the City of Detroit and suburban districts, industries, runoff from urban and agricultural lands, and effluent from CSOs flows into the Detroit River and hence to the lower Great Lakes (Lin, 1994; Roginski, 1981; U.S. EPA and EC, 1988). During 1979-1980, major monitoring and modeling work on the City of Detroit Section 201 Final Facilities Plan was conducted. Two reports, Quantity and Quality of CSO Volumes II and III, (Giffels et al, 1980) document that work, and cited CSOs as a source of conventional and toxic concentrations to the Detroit River. The characterization of the Detroit River CSO loadings is discussed in the Detroit River Remedial Action Plan Report (MDNR and MOEE Reports, 1991 and 1996). The chemical 
analysis of wastewater treatment plant influent, as a measure of sources of conventional and toxic contamination for the Detroit River, was presented by Kummler et al. (1996). The Detroit River Combined Sewer Overflows Toxic Sampling Project, Phase 2, Final Report collected the effluent data from CSOs to the Detroit River during various storm events over varying land use (SEMCOG, 1997). Schroeter (1997) computed the annual flow volumes and concentration mass discharges from such sources as stormwater runoff, CSOs, and sewage treatment plant effluents for 47 urban centers located in seventeen Canadian Areas of Concern (AOCs). Urban centers were defined as entities with sewage treatment plants servicing populations greater than 1,000. Schroeter found high annual loadings of several categories of toxic contaminants including trace metals, total polychlorinated biphenyl (PCBs) and a few trace organic compounds. Gall et al. (1997) and Daniel et al. (1997) have also studied CSO's in Canada, and Cave et al. (1994) have studied CSOs to the Rouge River, to name but a few such studies.

\subsection{Description of the Study Sites}

Four sites, Conner Creek Sewer at Freud Avenue, Fischer Sewer at Burns Avenue, Twelfth Street Sewer at Rosa Parks Boulevard and Jefferson Avenue, and Schroeder Sewer at West Jefferson Avenue were selected for collecting CSO data in the Detroit River Toxics study (see Figure 13.1). All these outfalls discharge to the Detroit River when sewer capacity is exceeded. This system provided hourly pollutant concentrations from CSO discharges throughout the year 1994-1995 during wet weather events for four locations. The CSO areas were sampled between 30 and 80 times for inorganic pollutants and between 14 and 22 times for organic pollutants depending on the site. These samples represented between 8 and 17 storms during which one or more combined sewers overflowed. In general, metal and non-metal inorganic pollutants were detected at all sites while many organic pollutants were not detected. However, flow rates at Rosa Park (Twelfth Street) Fischer and Schroeder were insignificant. The four CSO areas were monitored by the USGS and the City of Detroit to characterize water quantity and quality and to calculate pollutant loads from CSO discharges during wet weather events. To identify and quantify contaminant loads, automated, unattended gaging stations were designed and installed by the USGS. Water velocity, stage, discharge and precipitation were measured continuously and recorded at 5-minute intervals. Water quality samples were collected at discrete times during each storm and analyzed for inorganic and organic pollutants. This technology provides the ability to analyze CSO areas associated with land use, contaminated 307 sites, percent impervious, etc., to determine how they relate to other CSO areas. 


\subsection{Experimental Analysis}

For purposes of pollutant mass load calculations, the flow velocity was measured at each site and water-quality samples for analysis of selected pollutants were taken (SEMCOG, 1997).

\subsubsection{Flow Discharge Determination}

The flow velocity was measured at each site with either a channel-mounted fourtransducer-array acoustic velocity meter (AVM) or an upward-loading, bottommounted Doppler flow meter. The former was installed to measure flow velocity under backwater conditions and a stilling well with a shaft encoder installed to measure the stage (Conner Sewer), and the latter for measuring stage and velocity (Fisher Sewer, Twelfth Street Sewer, and Schroeder Sewer). Using standard USGS methods, physical discharge measurements in relation to the AVM velocity and stage data at Conner Sewer were conducted. At the other three sites, Doppler meters calculated discharge as a function of other measured parameters, stage, and velocity, and as a function of certain user input information about size, shape, slope, and construction of the sewer pipe. The Doppler sensor directly measured average velocity throughout the flow stream and an integral pressure transducer measured liquid depth (stage) to determine flow area. Using this information, the discharge volume was calculated.

At each site, a heated tipping-bucket rain gage was mounted on the roof of the gage house to measure precipitation. A refrigerated sampler was installed to collect and hold water-quality samples for analysis of selected pollutants. A data logger was used to store all data from the flow meter and the rain gage, to analyze flow and precipitation data, and to initiate automatic sampling based on this analysis. A cellular phone was installed to allow two-way communication between gage instruments and field personnel.

\subsubsection{Water Quality Sample Collection}

Samples for water quality analyses were collected at each site using a refrigerated (at $4^{\circ} \mathrm{C}$ ) automatic water sampler. Each sampler contained four ten-liter glass jars with teflon lids. Samples were drawn through $3.5 \mathrm{~m}$ of $10 \mathrm{~mm}$ Teflon-lined tubing at Conner Sewer, through $8 \mathrm{~m}$ of $10 \mathrm{~mm}$ Teflon-lined tubing at Fisher Sewer, through $12 \mathrm{~m}$ of $10 \mathrm{~mm}$ Teflon-lined tubing at Twelfth Street Sewer, and $2.75 \mathrm{~m}$ of $10 \mathrm{~mm}$ Teflon-lined tubing at Schroeder Sewer, to near the pump head. At the pump head, $15 \mathrm{~cm}$ of $10 \mathrm{~mm}$ polyethylene tubing was required to provide flexibility. The pump was operated at its lowest rate to prevent sample aeration. Water-quality samples were collected by use of suction lift samplers employing a peristaltic pump as "automatic grabs" (U.S.EPA, 1985). Water-quality samples 
at all sites were collected using flow-weighted composites. Further analysis of the data will make it possible to calculate pollutant loads to the Detroit River from each CSO sampled, but those calculations were not conducted as part of the original USGS study, and hence were not included in the final report (SEMCOG, 1997).

The Detroit Waste Water Treatment Plant (WWTP) lab provided analyses for conventional constituents and metals. Analytical protocols, including minimum detection levels, holding times, and quality assurance, were required by 40 CFR part 136, and by the standard operating procedures (SOPs) of the laboratory providing analysis (USGS and DWSD, 1994). Selected metals were measured by graphite-furnace atomic absorption (GFAA). More detail on the methodology may be found in the report by SEMCOG (1997).

\subsection{Results and Discussions}

Atmospheric transport and desorption of chemical contaminants, and industrial effluents to the system provide a source for a variety of toxic chemicals through CSOs to the Detroit River (Arimoto, 1989; MDNR, 1993). CSOs have been demonstrated to be a major source of conventional and toxic contamination to the Detroit River. In our studies, we focused on the Conner Creek CSO which represents a site with heavy industrial areas, and is a major source of contamination of the Detroit River.

The concentrations of 54 constituents and the discharges of the CSOs to the Detroit River were recorded in the CSO data during 1994-1995. The calculations of the mean concentrations (selected heavy metals) in the Conner Creek CSO to the Detroit River, based on USGS measurements for Conner, are given in Table 13.1:

Table 13.1 Monthly mean concentrations and standard deviation of selected constituents at the Conner Creek CSO to the Detroit River in 1995.

\begin{tabular}{ccccccccc}
\hline & $\mathrm{N}^{*}$ & $\mathrm{Cd}$ & $\mathrm{Cr}$ & $\mathrm{Cu}$ & $\mathrm{Fe}$ & $\mathrm{Pb}$ & $\mathrm{Zn}$ \\
\hline & & $\mathrm{ug} / \mathrm{L}$ & $\mathrm{ug} / \mathrm{L}$ & $\mathrm{ug} / \mathrm{L}$ & $\mathrm{ug} / \mathrm{L}$ & $\mathrm{ug} / \mathrm{L}$ & $\mathrm{ug} / \mathrm{L}$ \\
\hline Jan & 6 & $9.7 \pm 5.2$ & $76.7 \pm 104$ & $39.8 \pm 16$ & $2755 \pm 977$ & 50 & $198 \pm 61$ \\
March & 4 & $3.5 \pm 4.0$ & $18.8 \pm 20$ & $39.3 \pm 19$ & $2925 \pm 1639$ & $8.75 \pm 73$ & $147 \pm 74$ \\
April & 3 & $7.0 \pm 3.0$ & $15.3 \pm 5.0$ & $23.3 \pm 5.7$ & $1992 \pm 955$ & $15.3 \pm 5.0$ & $113 \pm 49$ \\
May & 1 & 11.8 & 28 & 22 & 1656 & 10 & 111 \\
July & 4 & $0.65 \pm 0.9$ & $61 \pm 74$ & $69 \pm 95$ & $8980 \pm 9993$ & $82 \pm 128$ & $309 \pm 422$ \\
Oct. & 6 & $5.8 \pm 6.7$ & $38.3 \pm 32$ & $46.6 \pm 41$ & $5570 \pm 4239$ & $50 \pm 56$ & $250 \pm 247$ \\
Nov & 2 & $3.8 \pm 2.5$ & $9.1 \pm 5.7$ & $34.6 \pm 18$ & $3275 \pm 971$ & 10 & $126 \pm 29.6$ \\
Average & 26 & $5.8 \pm 5.2$ & $42 \pm 61$ & $42.8 \pm 41.5$ & $4298 \pm 4687$ & $40 \pm 57$ & $200 \pm 199$ \\
\hline
\end{tabular}

$* \mathrm{~N}=$ number of samples 
No wet weather events were observed during February, August, September, and December at the Conner site (1995) and hence there is no data record for the pollutant concentration measurements during those months. Flow and rainfall data retrieval was accomplished by remote phone connection to a main-frame computer in the Madison, Wisconsin District office of the USGS. A program was written that called each gage at about 5:00 a.m. each day. This program functioned well, and the only difficulties encountered were occasional communication failures due to weather interference with the cellular phones installed at each gage. The USGS principal investigator, Mike Sweat, has stated that he believes that no events were missed during the 1995 observation year, so Table 13.1 represents the full year.

The purpose of this work is to convert the USGS measurements of flow and concentrations into mass loadings, which can be compared with previous estimates of Detroit River loadings (Giffels et al, 1980). The above results probably provide upper limits for 1995, as the frequency of data collection did not allow a fine temporal grid for integration purposes. Moreover, in these data sets, there are many more flow measurements than concentration measurements. Hence, the total flow is much more accurately known than is the concentration profile. Under these circumstances, an alternative estimate of the loadings can be made by summing the event-averaged volume multiplied by the event (time) averaged concentration. While this is not strictly valid, it presents another estimate. Using these assumptions, a second estimate of the loadings was calculated, which we refer to as the USGS method.

Thus, two different estimation methods have been developed to use the USGS flow and concentration data to calculate loadings. The first estimate was calculated by dividing the wet weather data into eight events. In these calculations, the loading was estimated as the integral of the instantaneous flow rate times the instantaneous concentrations over the events. This method is called the Load II method. The instantaneous volumetric flow rate at the time of sample collection was used. The second estimate (using USGS calculations) was based on the integral of volumetric flow rate times the average grab concentrations (not volumetrically averaged). This method is called the USGS method. Calculated event and annual loads of selected constituents for CSO Detroit River in Conner are represented in Tables 13.2 and 13.3.

A comparison between results of the two estimation techniques are given in Table 13.3. Load II results (calculated through the eight 1995 wet weather events) for selected elements are quite similar to the values calculated by the USGS method.

The ratio estimator for estimating pollutant loadings developed by Beale (1962), was not included in our studies. The estimate is derived from a ratio of the mean of measured loads to the mean of flows when loads were measured. This ratio is used with the mean of the actual flow to obtain the estimate. This method 
Table 13.2 Load calculations using an eight event division (Load II).

\begin{tabular}{lrrrrrr}
\hline & $\mathrm{Cd}$ & \multicolumn{1}{c}{$\mathrm{Cr}$} & $\mathrm{Cu}$ & \multicolumn{1}{c}{$\mathrm{Fe}$} & \multicolumn{1}{c}{$\mathrm{Pb}$} & \multicolumn{1}{c}{$\mathrm{Zn}$} \\
\hline Event1 & \multicolumn{1}{c}{$\mathrm{Kg}$} & \multicolumn{1}{c}{$\mathrm{Kg}$} & \multicolumn{1}{c}{$\mathrm{Kg}$} & \multicolumn{1}{c}{$\mathrm{Kg}$} & \multicolumn{1}{c}{$\mathrm{Kg}$} & \multicolumn{1}{c}{$\mathrm{Kg}$} \\
Event2 & 0.65 & 0.62 & 6.78 & 485.5 & 0.86 & 25.21 \\
Event3 & 0.010 & 0.27 & 0.46 & 51.38 & 0.25 & 3.10 \\
Event4 & 0.20 & 0.023 & 0.42 & 117.13 & 0.29 & 2.16 \\
Event5 & 0.56 & 2.23 & 1.75 & 146.42 & 0.79 & 8.83 \\
Event6 & 3.79 & 65.06 & 75.33 & 5638.28 & 92.59 & 329.45 \\
Event7 & 0.024 & 0.72 & 1.20 & 529 & 1.20 & 10.83 \\
Event8 & 2.23 & 8.06 & 10.10 & 1278.68 & 10.22 & 59.51 \\
Annual & 0.78 & 2.72 & 15.10 & 1403.6 & 3.87 & 42.93 \\
Loads & $\mathrm{Kg} /$ year & $\mathrm{Kg} /$ year & $\mathrm{Kg} /$ year & $\mathrm{Kg} /$ year & $\mathrm{Kg} /$ year & $\mathrm{Kg} /$ year \\
mansm & 8.24 & 80 & 111 & 9650 & 110 & 482 \\
\hline
\end{tabular}

Table 13.3 Comparison of results of estimated annual loads for 1995 at Conner Creek in $\mathrm{kg} /$ year.

\begin{tabular}{lrrrrrrr} 
& $\mathrm{Cd}$ & $\mathrm{Cr}$ & $\mathrm{Cu}$ & $\mathrm{Fe}$ & $\mathrm{Pb}$ & $\mathrm{Zn}$ \\
\hline Load II & 8.24 & 80 & 111 & 9650 & 110 & 482 \\
USGS & 13.78 & 89 & 131 & 14992 & 127 & 620 \\
\hline
\end{tabular}

is ideally suited to those situations where there is an abundance of flow information for a tributary, but relatively little concentration information. This method will be used in future studies in an attempt to improve accuracy.

\subsection{Comparison With Previous Studies}

In the report, Quantity and Quality of Combined Sewer Overflows, 1979, using the experimental data of Giffels et al, (1980), the mean concentrations of the selected metals $(\mathrm{Cd}, \mathrm{Cr}, \mathrm{Cu}, \mathrm{Fe}, \mathrm{Pb}, \mathrm{Zn})$ were calculated. Those data were compared with the (USGS) 1995 CSO measurement data (SEMCOG, 1997). The mean CSO concentrations during 1979 were analyzed in tables by Giffels et al., in Report Volumes II and III for all sites and all events.

Similarly, the analytical results (concentrations) for 1979, were coupled with the volumetric data to calculate the annual average mass loadings by ( $\mathrm{kg} /$ year) of the selected constituents for the Detroit River for the Conner site. Table 13.4 gives the mean constituent concentrations and the annual average 
loadings of the Conner Creek CSO for Detroit during 1979. The loadings obtained at Conner in 1979 were estimated to be $14 \%$ of the total CSO annual volume from CSOs emitting to the Detroit River sites in 1979.

Table 13.4 Mean constituent concentrations and annual average loadings of CSO to the Detroit River at the Conner Creek site during 1979 (Giffels, Black and Veatch, 1980).

\begin{tabular}{llr}
\hline Parameters & $\begin{array}{l}\text { Mean concentrations, } \\
\mu \mathrm{g} / \mathrm{L}\end{array}$ & $\begin{array}{l}\text { Annual average loadings, } \mathrm{kg} / \text { year } \\
\text { (estimate) }\end{array}$ \\
\hline Cadmium, $\mathrm{Cd}$ & $30.4(4)$ & 362.6 \\
Chromium, $\mathrm{Cr}$ & $100(1)$ & 3952.2 \\
$\mathrm{Copper}, \mathrm{Cu}$ & $110(1)$ & 1918 \\
Iron, $\mathrm{Fe}$ & $3220(1)$ & 335720 \\
Lead, $\mathrm{Pb}$ & $210(1)$ & 3948 \\
$\mathrm{Zinc}, \mathrm{Zn}$ & $180(1)$ & 4900 \\
\hline ( ) number of observations & &
\end{tabular}

The comparison between the 1979 Quantity and Quality of CSO predictions (Giffels et al, 1980) and 1995 CSO Detroit River (USGS) measurements for the mean concentrations and the average loadings (Load II method) of the selected constituents for Conner site is given in Figures 13.2 and 13.3. The Fe loadings for 1979 are divided by 20 in order to better display the results. Note that the 1995 Detroit River CSO concentrations and loadings are substantially lower than the 1979 Detroit River CSO results; this can be attributed to the city of Detroit's industrial pretreatment program, the general decline of industrial activity in the area, the concentrated efforts of industries to reduce discharges through pollution prevention, and a dry rain year. The major reduction in loadings was caused by a reduction in discharge volume, from an estimated 2.3 billion gallons in 1979 to a measured 0.012 billion gallons in 1995 .

This observation is in general agreement with the results obtained by Schroeter (1997). He found that CSOs contributed the lowest loadings compared to sewage treatment plant effluents, as measured by trace metals, particularly $\mathrm{Zn}$, $\mathrm{Pb}, \mathrm{Cu}$, and $\mathrm{Ni}$. He attributed these decreasing values to the development of the remedial action plans, as we do.

\subsection{Conclusions}

Based on the analysis of the CSO Detroit River pollution at Conner for 1979 and 1995, we offer the following conclusions: CSO loadings of 1995 compared to 1979 for $\mathrm{Cd}$ have been reduced by $96-98 \%, \mathrm{Cr} 98 \%, \mathrm{~Pb} 97 \%$, Fe 96-97\%, and for $\mathrm{Cu}$ and $\mathrm{Zn} 93 \%$ and $87-90 \%$, respectively. The annual loadings from Conner 


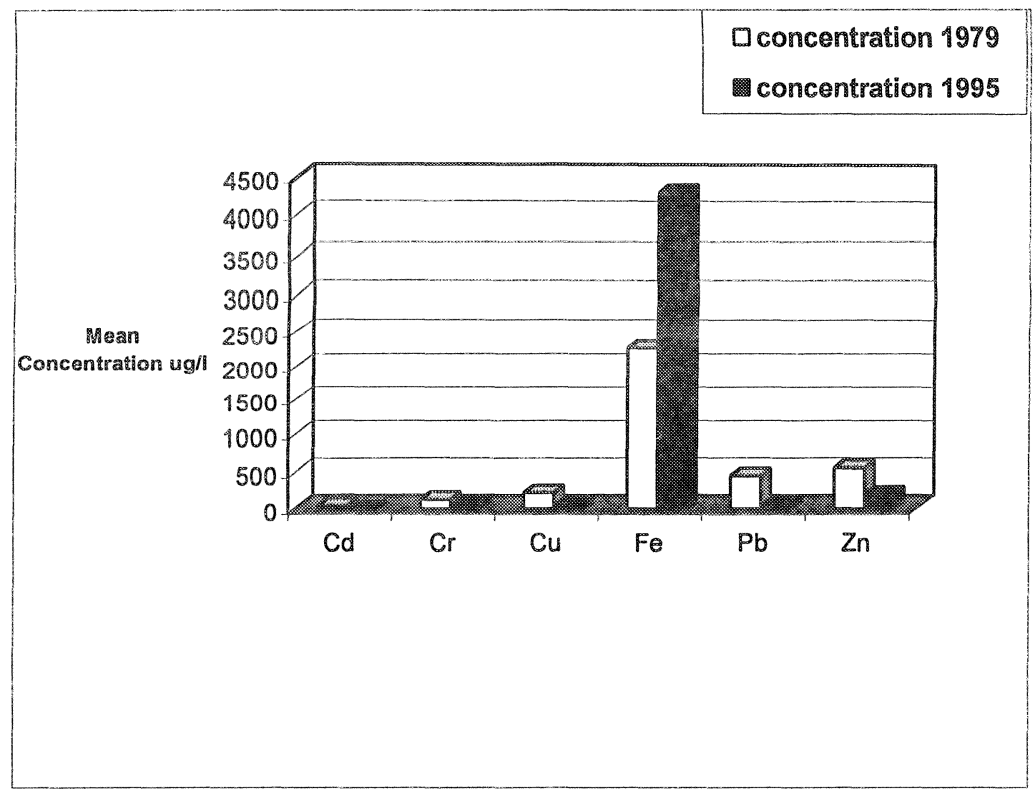

Figure 13.2 Comparison between 1979 and 1995 of the selected mean concentration for all CSO sites to the Detroit River. (Fe x 20).

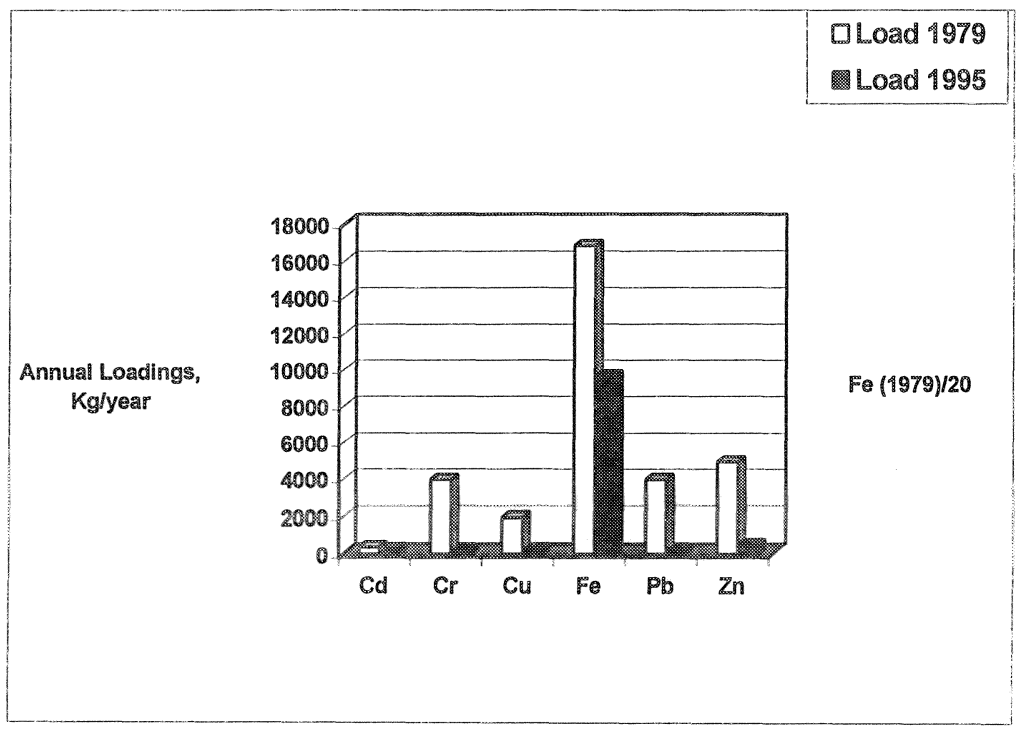

Figure 13.3 Comparison between 1979 and 1995 of the selected annual loadings for the Conner Creek CSO to the Detroit River. (Fe x 20). 
to the Detroit River improved by the reduction of most pollutant loadings because of reduced industry input through Detroit's industrial pretreatment program for the discharges. Additional work is being devoted to providing an estimation and evaluation of mean concentrations of the pollutants during stormwater events for several land uses, to support the above analysis, using 1995 sampling data from selected Detroit River sites.

\section{References}

Armito, R. 1989. Atmospheric Deposition of Chemical Contaminants to the Great Lakes. J. Great Lakes Res., 15(2). pp: 339-356.

Beale, E.M.L. 1962. Some uses of computers in operational research. Industrielle Organisation 31:51-52.

Cave, K., Quasebarth T. and E. Harold, 1994. Technical memorandum of selection of stormwater pollutant loading factor, No. RPO-MOD-TM34.00: Rouge River National Wet Weather Demonstration Project.

Daniel, S.; Marek, S; Jiri, M; Eleonora, F; Lubomir, H; Dusan, R; Stefan, S; Jan, I and Juraj, N, 1997. A Case Study of Combined Sewer Overflow Pollution: Assessment of Sources and Receiving Water Effects, Water Quality Res. J. Canada, 32 (3), pp. 563578.

Gall, B.; Averill.D and Weatherbe.D, 1997. Modeling Design and Optimization of a

Combined Sewer Overflow Treatment System, Water Quality Res. J.Canada, 32 (1), pp. 139-153.

Giffels, Black and Veatch, 1980. Quantity and Quality of Combined Sewer Overflows Vol. II and III, Report, CS-806, Final Facilities Plan, Interim Report, City of Detroit Water and Sewage Department.

Kummler R., C. C. Lin and Yung-Yun Rhee, 1996. Analysis of Wastewater Treatment Plant Influent Data, Proceedings of the Fifth International Conference on Energy and Environment, Cairo, Egypt, pp. 817-83.

Lin, C. C., 1994. Modeling the Detroit River Aquatic and Sediment Systems, Ph.D. dissertation, Dept. of Chemical Engineering, Wayne State University, Detroit, MI, pp.1-5.

MDNR , 1993. Michigan Department of Natural Resources. Proposed List for Michigan Sites of Environmental Contamination.

MDNR and MOEE, 1996. Michigan Department of Natural Resources and Ontario Ministry of the Environment and Energy, Remedial Action Plan for Detroit River Area of Concern, Biennial Report.

MDNR and MOEE, 1991. Michigan Department of Natural Resources and Ontario Ministry of the Environment and Energy, Remedial Action Plan Stage 1 for Detroit River Area of Concern, Sources in Ontario Areas of Concern.

Roginski, G. T, 1981. A Finite Difference Model of Pollutant Concentrations in the Detroit River From Combined Sewer Overflows, Ph.D.dissertation, Dept. of Chemical and Metallurgical Engineering, Wayne State University, Detroit, MI, pp. 1-10.

Schroeter, H.O., Toxic Contaminant Loadings from Municipal Sources in Ontario Areas 
of Concern, Water Quality Res. J. Canada, 32 (1), pp. 7-22, 1997.

Southeast Michigan Council of Governments (SEMCOG), Detroit River Combined

Sewer Overflow Toxic Sampling, Project Phase 2 (FY93) Final Report, 1997. U.S. EPA, NEIC Policies and Procedures, EPA-330/9-78/DD-R, Revised, June 1985. U. S. EPA and EC., Upper Great Lakes Connecting Channels Study, Vol. II, Final Report, pp. 458-476, 1988. 
